\title{
"Você fez, agora aguenta": Análise das narrativas de violência obstétrica no Facebook
}

\author{
You dit it, now you deal with it!": Analysis of obstetric violence narratives \\ on Facebook
}

\section{Veronica Haacke}

Mestra em Comunicação e Territorialidades e Bacharela emjornalismo, ambos pela Universidade Federal do Espírito Santo. Atuadesde 2013 como pesquisadora, desenvolvendo trabalhos baseadosem dados de mídias sociais, fazendo interlocução com as áreas deeducação, direitos humanos, movimentos sociais e saúde.

\section{Fabio Malini}

Professor Associado III no Departamento de Comunicação Social da Universidade Federal do Espírito Santo, onde coordena o LABIC (Laboratório de Pesquisa sobre Imagem e Cibercultura). Atua na pesquisa aplicada no campo da ciência de dados, discursos políticos e análises de redes sociais.

\section{RESUMO}

A internet possibilitou novas e diferentes trocas comunicacionais e relacionais entre os usuários, como também entre a produção e compartilhamento de conteúdo, sendo uma importante aliada dos movimentos sociais contemporâneos, tanto como ferramenta de mobilização quanto para a promoção da conscientização de suas pautas para o público. Entre esses movimentos destaca-se o feminismo, que devido aos seus novos contornos pode-se dizer que hoje experencia uma nova fase, denominada como Quarta Onda. Uma das principais pautas dessa onda é a discussão acerca da violência de gênero, que entre suas formas está a violência obstétrica. Este artigo tem por objetivo compreender o conteúdo dos comentários presentes em páginas do Facebook que discutem a violência obstétrica. Para tanto, foram utilizados recursos metodológicos, tanto da ciência de dados quanto da comunicação, para realizar a coleta, organização, sistematização, análise e visualização dos dados.

PALAVRAS-CHAVE: Feminismo; Redes Sociais Digitais; Violência de Gênero; Violência Obstétrica; Relatos

Dossiê Crise, Feminismo e Comunicação - https://revistaecopos.eco.ufrj.br/

ISSN 2175-8689 - v. 23, n. 3, 2020

DOI: 10.29146/eco-pos.v23i3.27616 


\section{ABSTRACT}

The internet enabled new and different communication and relational exchanges between users, as well as between content production and sharing, and has been an important ally of contemporary social movements; both as a tool for mobilization and for promoting the awareness of their agendas to the public. Among these movements, feminism stands out, which due to the new contours, we can highlight that today is a new phase, called the Fourth Wave. One of the main guidelines of this wave is the discussion of gender violence, among whose forms is obstetric violence. This article aims to understand the content of comments on Facebook pages that discuss obstetric violence. For this, we use methodological resources from data science and communication, to perform the collection, organization, systematization, analysis and visualization of the data. KEYWORDS: Feminism; Digital Social Networks; Gender Violence; Obstetric Violence; Stories

\section{RESUMEN}

Internet permitió nuevas y diferentes comunicaciones y intercambios relacionales entre usuarios, así como entre la producción y el intercambio de contenidos, siendo un importante aliado de los movimientos sociales contemporâneos, tanto como herramienta de movilización como para promover la conciencia pública de sus agendas. Entre estos movimientos destaca el feminismo, que por sus nuevos contornos, podemos resaltar que hoy vive una nueva fase, denominada Cuarta Ola. Uno de los principales lineamientos de esta ola es la discusión sobre la violencia de género, que entre sus formas es la violencia obstétrica. Este artículo tiene como objetivo comprender el contenido de los comentarios en las páginas de Facebook que tratan sobre la violencia obstétrica. Para esto, se utilizaron recursos metodológicos, tanto de la ciencia de datos como de la comunicación, para realizar la recolección, organización, sistematización, análisis y visualización de los datos. PALABRAS CLAVE: Feminismo; Redes sociales digitales; Violencia de género; Violencia obstétrica; Cuento

\section{Introdução}

A plataformização da vida (VAN DIJCK, 2018) tem instituído uma sociabilidade programada (BUCHER, 2018) em nossa atualidade. Nessa acepção, nossos modos de estar juntos são governados e ordenados por softwares e algoritmos desenvolvidos por corporações tais como Facebook, Twitter ou Microsoft. Isso implica dizer que nossos valores, expressões e encontros passaram a ser moldados

Dossiê Crise, Feminismo e Comunicação - https://revistaecopos.eco.ufrj.br/

ISSN 2175-8689 - v. 23, n. 3, 2020

DOI: 10.29146/eco-pos.v23i3.27616 
e orientados no interior dessas plataformas, que investem nas relações sociais ao nos indagar sobre nossas memórias, ao nos notificar sobre comentários que fazem acerca de nossas declarações ou ao reportar espaços onde nossas experiências comuns podem ser acolhidas.

Longe de um determinismo tecnológico, a apropriação crítica do feminismo das plataformas digitais está subvertendo o viés determinista do poder algorítmico, transmutando-o em um campo de ação em rede, ao curto-circuitar essa lógica algorítmica quando transforma a "amizade computável" (BUCHER, 2018) - base de onde se extrai o business nas plataformas de redes sociais - em um mecanismo para fundar espaços coletivos de denúncias; "inventando pessoas" (GILLESPIE apud BUCHER, 2018, p. 9) que vão no sentido contrário do significado de "amei/tenho interesse" das curtidas, ao expor agudos problemas que afligem as mulheres, funcionando como gatilho para insurreições digitais feministas (COSTA, 2019). Estas se beneficiam da lógica descentralizada das redes para compartilhar questões do movimento, principalmente sobre violência contra mulher. "A grande questão que une todas as tendências do novo feminismo, traduzida numa infinidade de perspectivas, desdobramentos, nuances e percepções, é a violência contra a mulher" (BOGADO, 2019, p. 347). Esse tipo de violência "ocorre motivada pelas expressões de desigualdades baseadas na condição de sexo, a qual começa no universo familiar, onde as relações de gênero se constituem no protótipo de relações hierárquicas" (BANDEIRA, 2014, p. 450).

Entre as tipificações de violência gênero, encontramos a violência obstétrica, foco deste trabalho. Este tipo de violência pode ser qualquer procedimento ou ato direcionado à mulher gestante, parturiente, puérpera (mulher que deu à luz recentemente) ou mulher que passou por processo de abortamento, com ações pautadas pelo desrespeito à autonomia e direito da mulher sobre seu próprio corpo (PARTO DO PRINCÍPIO, 2012). 
Em um cenário de disputas e controvérsias sobre controle do corpo da mulher, violências de gênero e formas de parir, páginas presentes no Facebook se direcionam às discussões de violência obstétrica. A partir desses territórios ocorre uma articulação de mulheres "movidas por uma grande contrariedade e insatisfação em relação à institucionalização do corpo feminino e à violência obstétrica" (LUZ; GICO, 2017, p. 152). São relatos e experiências compartilhados a fim de clarificar acerca das intervenções e violências na assistência ao parto, buscando, além do partilhar de informações, a retomada do protagonismo feminino no momento de partejar.

Esse artigo pretende, então, revelar as narrativas da violência obstétrica compartilhadas em páginas do Facebook - que se destinam às discussões da temática, bem como de discussões sobre o movimento feminista - entre os anos de 2018 e 2019, visibilizando relatos - antes privados - que expõem os diferentes registros de indignação e denúncia contra práticas de poder inscritas na relação médico-paciente. É um trabalho que requereu um manejo complexo dos dados extraídos do Facebook, uma vez que 19.677 comentários e 797 posts tiveram que ser processados e visualizados através de ferramentas do campo da ciência de dados - aqui representados pelo extinto aplicativo do Facebook - Netvizz; pelo software de sistematização de dados - Ford desenvolvido pelo Laboratório de estudos sobre Imagem e Cibercultura (LABIC); e o software de criação de grafos Gephi (todos estes apresentados na seção de metodologia) -, demandando assim novos métodos para lidar com novos objetos de pesquisa.

Trabalhos teóricos relacionados: violência obstétrica como violência de gênero

Como pontuado anteriormente, uma das marcas do movimento feminista de quarta onda ${ }^{1}$ é a presença intensa de pautas acerca da violência de gênero. Aliada a

\footnotetext{
${ }^{1} \mathrm{Na}$ contemporaneidade se caracteriza uma nova configuração do feminismo, sendo esta denominada como Quarta Onda. Decerto, novos contornos no movimento foram atribuídos e sujeitos políticos dotados de novas formas de organização são reconhecidos, conferindo

Dossiê Crise, Feminismo e Comunicação - https://revistaecopos.eco.ufrj.br/

ISSN $2175-8689$ - v. 23, n. 3, 2020

DOI: 10.29146/eco-pos.v23i3.27616
} 
esta questão, pontua-se acerca de ser um movimento centrado nas experiências individuais vividas, em que se constroem uma identidade coletiva a partir da individualidade. Uma das formas de mobilização e luta contra a violência se dá a partir do compartilhamento de histórias das mulheres que sofreram algum tipo de violação.

Entende-se por violência de gênero como uma "afronta infligida a uma mulher pelo fato de ela nascer mulher" (VARIKAS, 2016, p. 17), sendo que essas "agressividades constatam a subordinação feminina e o poder dos homens sobre as mulheres" (SOUZA, 2015, p. 717). Ou seja, “o simples fato ou condição de ser mulher" (VANZ, 2017, p. 54) faz com que ela seja alvo de violência.

São diversas as formas em que a violência de gênero se manifesta, podendo ela ser de caráter físico, institucional, moral, patrimonial, sexual, psicológica (TELES; MELO, 2017) e obstétrica. A última, de definição ainda recente, tem como base qualquer ação violenta destinada à mulher gestante, parturiente ou puérpera, com ações que incidem sobre seus corpos, desrespeitando seus direitos e autonomia.

A violência obstétrica, por pautar-se na inferioridade física e moral da mulher enquanto paciente, segundo Aguiar (2010), permite que seu corpo e a sua sexualidade sejam objetos de controle da sociedade através da prática médica. Assim, pode ser caracterizada como violência de gênero, cuja definição mais ampla é "qualquer ato ou conduta baseada no gênero, que cause morte, dano ou sofrimento físico, sexual ou psicológico à mulher, tanto na esfera pública como na esfera privada" (CONVENÇÃO BELÉM DO PARÁ, 1994).

características singulares dessa onda se comparada às demais. Sua singularidade não vem apenas de ser um movimento com a presença de mulheres cada vez mais jovens. Ele também vem com o intenso uso de redes e das mídias sociais digitais, em que a capacidade multiplicadora da internet (COSTA, 2019) possibilita com que o movimento atinja uma amplitude até então não experienciada. A partir das potencialidades das redes, o feminismo passa a se construir como um movimento marcado pela descentralização e horizontalidade, privilegiando a autonomia e ação direta entre os pares.

Dossiê Crise, Feminismo e Comunicação - https://revistaecopos.eco.ufrj.br/

ISSN 2175-8689 - v. 23, n. 3, 2020

DOI: 10.29146/eco-pos.v23i3.27616 
Compreendemos violência obstétrica como resultado de um processo histórico, cultural, social e econômico, que vai desde a objetificação e desvalorização da mulher e de seus corpos, estabelecidas a partir das distinções de gênero e a violência pautada nessa diferença; medicalização ${ }^{2}$ do corpo feminino, caracterizada pelo advento da medicina enquanto saber científico sobre os corpos; valorização do poder e conhecimento médico sobre a paciente; tecnocratização do parto e as altas taxas de cesáreas. Ela passa a ser caracterizada, então, como as intervenções e procedimentos, muitas vezes desnecessários - se forem de acordo à medicina baseada em evidências - aos quais as parturientes são direcionadas (AGUIAR, 2010). Sendo ainda marcada pelo uso inadequado da tecnologia em prol de um status e poder médico.

Vale contextualizar que o termo Violência Obstétrica ainda é recente, instituído em 2007, através de uma lei sancionada na República Bolivariana da Venezuela - Ley orgánica sobre el derecho de las mujeres a una vida libre de violencia. Além de pontuar acerca de outros tipos de violência direcionadas às mulheres, como esterilização forçada, violência doméstica, sexual, patrimonial e econômica, midiática, simbólica, e institucional, o documento traz, em seu artigo de número 51, a definição de Violência Obstétrica, caracterizada como "apropriação do corpo e processos reprodutivos das mulheres por profissionais de saúde, que se expressa pelo tratamento desumanizador, no abuso de medicalização e patologização dos processos naturais, trazendo consigo a perda da autonomia" (VENEZUELA, 2007, p. 8, tradução própria)

Ademais, pontua acerca dos atos constitutivos de violência obstétrica, demarcado por: não atender de maneira adequada às emergência obstétricas; obrigar a mulher a parir em posição supina; criar obstáculos para o contato imediato do

\footnotetext{
2 Com a concepção de corpo como um produtor econômico (FOUCAULT, 2017), sendo as mulheres, o corpo reprodutor por excelência (MAIA, 2010), é necessário que os processos relativos à reprodução sejam controlados, no caso, com o advento da medicina e de seu poder sobre os corpos das mulheres.
}

Dossiê Crise, Feminismo e Comunicação - https://revistaecopos.eco.ufrj.br/

ISSN $2175-8689$ - v. 23 , n. 3, 2020

DOI: 10.29146/eco-pos.v23i3.27616 
bebê com a mãe, mesmo sem causa médica justificada; alterar o processo natural do parto de baixo risco mediante técnicas de aceleração sem o consentimento da mulher; praticar o parto por via cesárea quando há condições para o parto natural e sem obtenção do consentimento voluntário (VENEZUELA, 2007).

[...] a violência obstétrica se configura como uma negação dos direitos humanos e dos direitos sexuais reprodutivos às mulheres. Ela compreende qualquer ato que venha provocar dano físico, emocional, psicológico a essa mulher fazendo com que a experiência do parto e do nascimento sejam sentidas de modo negativo. Ela ocorre desde o pré-natal até o pós-parto e tem relação direta com os profissionais que estão assistindo. Vale ressaltar que a violência obstétrica não é violência praticada apenas pelo médico obstetra, mas por qualquer pessoa dentro do campo da assistência, que vai da gravidez até o pós-parto. Pode ser pelo médico, enfermeiro, fisioterapeuta, por qualquer profissional que pratique dano a essas mulheres. (FREITAS, 2019, online $^{3}$ )

Em 2012, em parceria com o governo brasileiro, a Rede Parto do Princípio divulgou um dossiê sobre violência obstétrica intitulado "Parirás com dor". Compartilhado pelo site do senado brasileiro, o documento é composto de uma revisão bibliográfica sobre a temática e tem como foco reverter a situação brasileira em relação a esses tipos de atos intervencionistas e violentos.

A Rede elaborou uma tipificação própria para a abordagem de violência obstétrica no Brasil, abarcando ao máximo as situações de desrespeito. Assim, incluem para o conceito de violência as ações realizadas não apenas pelos profissionais de saúde, mas por todos aqueles que desrespeitam, de alguma forma, os direitos da gestante, parturiente e puérpera. Assim, estipula acerca de algumas ações que são consideradas como formas de violência, pontuadas por: proibição de acompanhante; restrição ao acompanhante mediante cobrança de taxas; episiotomia de rotina4; intervenções de verificação e aceleração do parto; falta de

3 Disponível em: https://www.ufpb.br/ufpb/contents/noticias/201cplano-de-parto-previneviolencia-obstetrica201d-alerta-pesquisadora-da-ufpb

${ }^{4}$ A episiotomia é uma cirurgia realizada na vulva, cortando a entrada da vagina com uma tesoura ou bisturi, algumas vezes realizada sem anestesia. No Brasil, essa prática ainda é realizada, mesmo sem evidências médicas, e executadas, na maioria das vezes, sem o consentimento da parturiente. A episiotomia de rotina foi contra-indicada pela OMS desde 1985, já que se configura como uma

Dossiê Crise, Feminismo e Comunicação - https://revistaecopos.eco.ufrj.br/

ISSN 2175-8689 - v. 23, n. 3, 2020

DOI: 10.29146/eco-pos.v23i3.27616 
esclarecimento e consentimento da paciente; manobra de kristeller5; restrição de posição para o parto; restrição da escolha do local de parto; cesáreas eletivas, por conveniência do médico, dissuasão da mulher, coação da mulher ou apologia à cesárea; atendimento desumanizador e degradante - omissão de informações, descaso e abandono, desprezo e humilhação, ameaça e coação, preconceito e discriminação, estigmatização, assédio e sadismo, culpabilização e chantagem, desconsideração dos padrões culturais, desrespeito a mulheres em situação de abortamento; apoio desumanizado à amamentação e separação mãe-bebê; cobranças questionáveis de acompanhamento ao parto; restrição da assistência ao parto (PARTO DO PRINCÍPIO, 2012).

Vale ressaltar que todas as práticas de violência obstétrica vão de encontro "com os preceitos jurídicos, assegurados principalmente pela Constituição Federal, como o direito à liberdade de escolha, à saúde adequada, à autonomia, à segurança e principalmente o direito a ter uma vida digna, o que engloba passar pelo processo da parturição de modo satisfatório" (SILVA; OLIVEIRA, 2019, p. 2)

Contudo, apesar desse conflito entre as ações de violência e os direitos humanos, no Brasil ainda não há uma legislação federal que versa acerca da violência obstétrica, sendo apenas observador projetos de leis de ordens estaduais e municipais (SILVA; OLIVEIRA, 2019).

Somando-se ao fato da não existência de uma legislação nacional, o tema violência obstétrica ainda se apresenta enquanto controverso, não havendo um consenso entre as esferas federais, médicas e a sociedade em geral. Como exemplo disto, podemos salientar o posicionamento oficial do Ministério da Saúde, divulgado em maio de 2019, que ressalta a improbidade do termo Violência Obstétrica, "pois acredita-se que, tanto o profissional de saúde quanto os de outras áreas, não tem a intencionalidade de prejudicar ou causar dano" (MINISTÉRIO DA SAÚDE, 2019, p.

violação dos direitos sexuais e reprodutivos da mulher, violando sua integridade corporal feminina. (PARTO DO PRINCÍPIO, 2012)

${ }^{5}$ A manobra de Kristeller é a força realizada por médicos ou enfermeiros sobre a barriga da mulher para ajuda no processo de parto. Uma força utilizada para empurrar a saída do bebê.

Dossiê Crise, Feminismo e Comunicação - https://revistaecopos.eco.ufrj.br/

ISSN $2175-8689$ - v. 23, n. 3, 2020

DOI: 10.29146/eco-pos.v23i3.27616 
1). Esse despacho oficial fez com que as discussões envolvendo a temática de violência obstétrica fossem reacendidas, principalmente, após a recomendação do Ministério Público Federal que exigiu que a mudança de posicionamento do MS, reconhecendo a violência obstétrica como causa do sofrimento de muitas mulheres.

Além dos impactos nas grandes mídias que abordaram as controvérsias do tema a partir dos posicionamentos das instituições federais, o debate nas redes sociais online - que já expunha casos individuais de violência, assim como divulgações audiovisuais e materiais informativos - se faz presente de forma intensa, sendo estes os motivos que levaram à compreensão proposta por este trabalho.

\section{Metodologia: cartografia de relatos de Violência Obstétrica no Facebook usando ferramentas de ciência de dados.}

Para analisar as conversações, os relatos e os conteúdos presentes nos comentários de páginas com foco nas discussões acerca da violência obstétrica, foi preciso estabelecer um caminho metodológico que articule ciência de dados e de comunicação. Dessa forma, a metodologia escolhida seguiu as etapas de: (a) mapeamento das páginas; (b) coleta de dados; (c) organização e análise; e (d) visualização de narrativas em grafos.

A primeira atividade foi o mapeamento das páginas relacionadas à temática de violência obstétrica. Para essa identificação, a partir da própria ferramenta de pesquisa do Facebook, foram iniciadas buscas com o uso de palavras chaves, assim como: "violência obstétrica"; "humanização do parto"; "violência no parto"; "violência gestante". Ao total, foram encontradas 98 páginas brasileiras que se destinavam às discussões em específico. Finalizado este processo, iniciaram-se as coletas, realizadas pelo aplicativo Netvizz $^{6}$ (ferramenta do próprio Facebook que

\footnotetext{
${ }^{6}$ Desde 2018 uma nova política do Facebook começou a restringir o acesso aos seus dados. Essa atualização limitou a coleta de dados, possibilitando apenas a coleta de aproximadamente 600 publicações por ano, e não mais os dados brutos gerais de cada páginas. Como um dos resultados da limitação, têm-se o encerramento das atividades do Netvizz em 21 de agosto de 2019.
}

Dossiê Crise, Feminismo e Comunicação - https://revistaecopos.eco.ufrj.br/

ISSN 2175-8689 - v. 23, n. 3, 2020

DOI: 10.29146/eco-pos.v23i3.27616 
possibilitava o acesso aos dados). As coletas resultaram um volume total de 37.363 publicações e 1.255.207 comentários.

Com o acesso aos dados, inicia-se o processo de mineração ${ }^{7}$, que corresponde à etapa anterior à análise e interpretação. Neste trabalho, ela ocorreu a partir de dois processos: a segmentação temporal e de conteúdo. 0 primeiro realizado para obter apenas os conteúdos compartilhados entre os anos de 2018 e 20198; enquanto o segundo ${ }^{9}$ para se destacar apenas as publicações e comentários que continham exclusivamente as discussões de violência obstétrica. Este processo resultou em um banco de dados com o volume de 797 publicações e 19.677 comentários presentes em 48 páginas.

Para as análises, escolhemos a análise de conteúdo como forma de interpretar as publicações e comentários com base em suas temáticas. Segundo Minayo (2007, p. 308), a análise de conteúdo "parte de uma leitura de primeiro plano das falas, depoimentos e documentos, para atingir um nível mais profundo, ultrapassando os sentidos manifestos do material”, sendo a análise temática uma forma de “descobrir os núcleos de sentido que compõem uma comunicação, cuja presença ou frequência signifiquem alguma coisa para o objeto analítico visado" (MINAYO, 2007, p. 316).

\footnotetext{
$7 \mathrm{O}$ data mining nada mais é do que um processo de filtragem dos dados, muito importante quando falamos sobre Big Data e grandes volumes de informações. Essa filtragem tem como objetivo sumarizar informações estratégicas presentes em grandes bancos de dados (DIAS, 2002)

8 Esse recorte temporal foi selecionado devido a sua atualidade, assim como por constarem acontecimentos que influenciaram a discussão nos sites de redes sociais, como também no ambiente midiático. Alguns desses acontecimentos são: 2018 - diretrizes da OMS acerca de menor intervenção médica nos atos de parturição; estreia do filme 0 Renascimento do Parto 2, com as discussões sobre violência obstétrica; repercussão do caso Janaína, que sofreu esterilização forçada por ordem do governo de São Paulo; 2019 - despacho do Ministério da Saúde acerca da improbidade do termo violência obstétrica; recomendação do Ministério Público Federal pelo reconhecimento da violência; assim como projetos de lei como a PL 96/2019 e PL 1195/19 que pautam acerca da violência obstétrica.

${ }^{9}$ Devido as páginas selecionadas abordarem outras temáticas, assim como ONU Brasil, Feminismo sem Demagogia e Cientista que virou Mãe, foi necessário esse processo para a delimitação dos conteúdos
}

Dossiê Crise, Feminismo e Comunicação - https://revistaecopos.eco.ufrj.br/

ISSN $2175-8689$ - v. 23 , n. 3, 2020

DOI: 10.29146/eco-pos.v23i3.27616 
Com a leitura prévia dos dados, juntamente aos estudos base para a compreensão sobre violência obstétrica, suas formas e consequências, foi possível a elaboração de uma legenda de categorias $^{10}$ norteadoras para a classificação dos dados de publicação e comentário.

A partir dos 19.677 comentários publicados entre 2018 e 2019 e coletados, iniciaram-se os processos de interpretação e categorização dos dados. Essa etapa foi fundamental para as posteriores análises e para entender as narrativas presentes no tema, assim como o posicionamento dos usuários.

Em um primeiro momento, é necessário frisar, assim como explicar - mesmo que de forma breve - acerca de algumas categorias, que não possuem o nome intuitivo, passíveis de dúvidas. Este é o caso da categoria Marcação, em que estão presentes os comentários que tem por finalidade marcar outros usuários, seja como forma de integrarem aquelas discussões ou então terem acesso às informações contidas nos posts e comentários. Já a categoria Desconsiderados estão inseridos os comentários que são fragmentos de outras conversas, portanto, não são possíveis de serem compreendidos de forma isolada). Ademais, há a presença da categoria Emojis, marcados pela presença apenas de figurinhas. Durante o processo de coleta também foi observado que algumas linhas da tabela que constavam na coluna de comentários vieram vazias, demarcados na categoria Vazios.

\footnotetext{
${ }^{10}$ Encontra-se na lista de legendas a presença de 30 categorias, sendo estas: apoio/sentimento; assistência; audiovisual; capacitação/cursos/; cesárea; emoji; escolha da mulher; evento/palestra; discussões sobre feminismo e machismo; humanização; indignação; informação; justiça; legislação; luta pelo fim da violência; marcação; não acredita na violência; mulheres negras e a violência obstétrica; nomenclatura violência obstétrica; parto normal; plano de parto; proibição parto domiciliar; questões políticas; recomendações OMS; relato de violência; relato; tipos de violência; violência; trabalho; violência de gênero;
} 
Tabela 1: Tabela com as categorias e suas respectivas quantidades de comentários

\begin{tabular}{cccc} 
Categoria comentário & Quantidade & Categoria comentário & Quantidade \\
\hline Marcação & 6.588 & Nomenclatura violência & 160 \\
Desconsiderados & 4.282 & Escolha da mulher & 137 \\
Audiovisual & 1.543 & Luta fim da violência & 126 \\
Apoio / sentimento & 1.378 & Humanização & 121 \\
Relato Violência & 1.079 & Questões políticas & 68 \\
Assistência & 706 & Evento / Palestra & 44 \\
Relato & 620 & Legislação & 40 \\
Justiça & 401 & Trabalho & 39 \\
Cesárea & 380 & Capacitação / curso & 38 \\
Violência & 340 & Discussões feminismo & 31 \\
Informação & 306 & Plano de parto & 27 \\
Vazio & 285 & Não acredita na violência & 24 \\
Emoji & 275 & Violência gênero & 17 \\
Indignação & 246 & Parto normal & 14 \\
Tipos de violência & 193 & Recomendações OMS & 7 \\
Proibição parto domiciliar & 161 & Mulheres negras e a & 1 \\
& & violênciaa &
\end{tabular}

Fonte: - Tabela própria, elaborada a partir da categorização dos 19.677 comentários coletados em 98 páginas do Facebook

Com base na tabela 1, percebemos que a categoria mais frequente é Marcação, com 6.588 comentários, apresentando 33,48\% do número total de dados. Ela está relacionada, principalmente, às postagens da categoria Relato de Violência (1.918), impulsionando para que demais usuários leiam os relatos presentes, seja como forma de conscientização ou como busca de pertencimento, para que outras mulheres reconheçam a si mesmas ou as suas experiências a partir do relato de terceiras. Os comentários também se relacionam aos posts destinados às discussões acerca do filme $O$ Renascimento do Parto ou demais documentários que 
abordam a temática de violência obstétrica, estando 1.360 comentários atrelados à categoria Audiovisual.

Os comentários presentes na categoria Audiovisual (1.543) estão reciprocamente ligados às publicações de mesmo tema, estabelecendo uma conversação acerca de dúvidas sobre o filme ou combinando com demais usuários de assistirem ao filme juntos.

Já a categoria Apoio/Sentimento está relacionada às publicações de Relatos de Violência (926), mostrando apoio às usuárias que compartilharam seus relatos. Também é interessante observar a incidência de comentários que estão atrelados às publicações de Tipos de Violência (238), que demonstram o medo das usuárias em passar por esses tipos de violência, assim como tristeza por ações como episiotomia, ponto do marido e manobra de kristeller ainda serem recorrentes na assistência ao parto.

Ao observar a categoria Relato de Violência, foco deste estudo, além de estarem relacionados às publicações também da categoria de Relato de Violência (339) e Tipos de Violência (454) - assim como observado anteriormente na análise de publicações - também se relacionam às categorias Justiça (67) e Cesárea (56). Em Justiça, após divulgação de médicos que foram punidos por causarem alguma violência à mulher, ou por saberem acerca do prazo para entrar com o processo, usuárias acabam por relatar suas experiências. Já os comentários que se relacionam à temática de Cesárea, contam suas experiências de cesáreas eletivas, de imposição da intervenção ou da enganação que os médicos contam para realizar a cirurgia, mesmo que de forma não necessária.

Já para a visualização dos dados em forma de grafos, devido ao foco do trabalho ser os conteúdos de relatos de violência, priorizou-se os 1.079 comentários desta 
categoria para a sua a partir de suas redes semânticas. Para tal, foi necessário a utilização do script Ford ${ }^{11}$, assim como da plataforma Gephi12.

A partir dos grafos criados pelas relações semânticas entre as palavras presentes nos comentários, foi possível perceber a associação de elementos textuais e as suas correlações. Assim, cada palavra representa um nó, sendo as arestas as conexões com os demais termos. Esse tipo de análise permite identificar como determinado conteúdo pode ser caracterizado por um termo, quais são suas frequências e como ele se estabelece na construção e representação de um discurso.

\section{Análise e discussões}

Para compreender as relações que as palavras estabelecem entre si, e assim, como constroem os discursos presentes nos comentários, foram elaborados grafos com base nos 25 termos mais utilizados em cada categoria de comentários. Destarte, constituem-se os clusters, ou seja, agrupamentos de palavras demarcados por cores diferentes, em que os termos se unem a partir da sua co-ocorrência e quantidades de aparições.

Imagem 1: Conexões entre os termos presentes na categoria Relato de Violência

110 Ford é um script desenvolvido pelo Laboratório de Estudos sobre Imagem e Cibercultura (Labic) capaz de realizar coletas e sistematização dos dados oriundos de sites de redes sociais. No presente trabalho, foi utilizado como forma de organizar os dados e gerar suas estatísticas. 0 script Ford-parse realizou uma análise automatizada, obtendo informações analíticas do conjunto de dados. Com o processo de parseamento dos dados, foi possível ter acesso às estatísticas como as principais palavras escritas e quantas vezes foram usadas (top_words).

$12 \mathrm{O}$ Gephi é um software livre que possibilita a criação e visualização de grafos a partir de diversos parâmetros. A partir de tabelas ou arquivos .gdf, é possível criar redes de dados, sejam eles referentes a uma rede de atores ou palavras, e perceber suas conexões. A partir do arquivo network.gdf, gerado a partir do top_words - dado este obtido a partir do processamento pelo Ford, foi possível realizar a construção dos grafos.

Dossiê Crise, Feminismo e Comunicação - https://revistaecopos.eco.ufrj.br/

ISSN 2175-8689 - v. 23, n. 3, 2020

DOI: 10.29146/eco-pos.v23i3.27616 


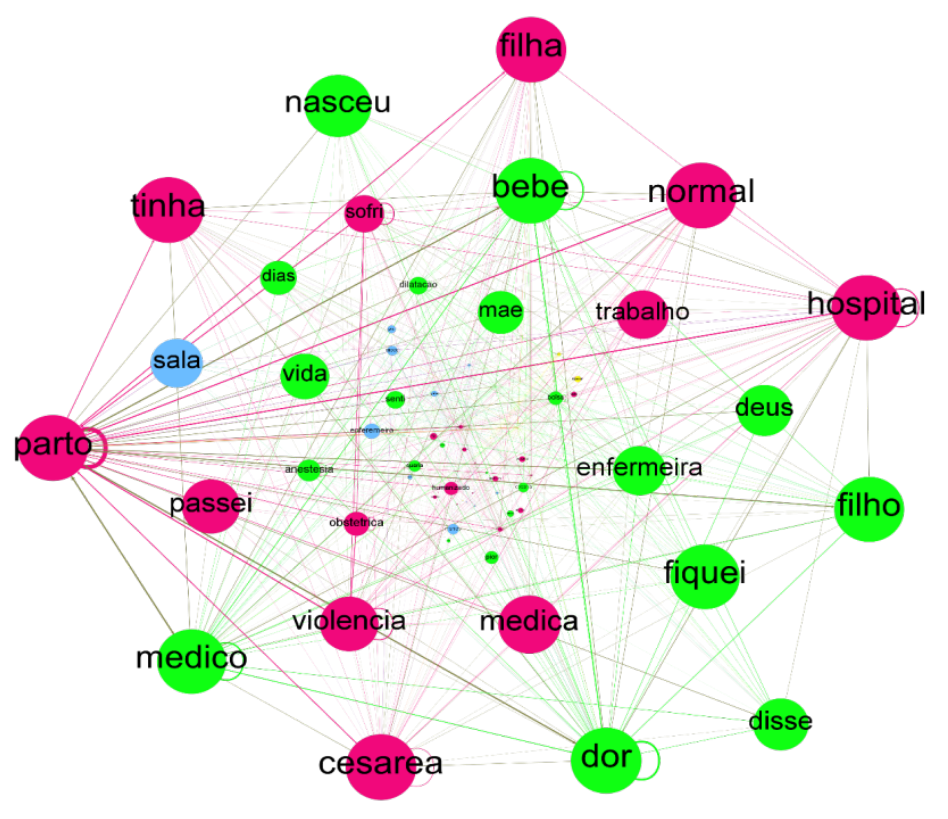

Fonte: - Grafo próprio criado a partir do Gephi

A imagem 1 representa o grafo formado a partir de 85 palavras referentes aos comentários de Relato de Violência e as 625 relações entre elas. Podemos observar que essa categoria se apresenta com uma baixa quantidade lexical, possibilitando a compreensão de que as palavras acabam por ser usadas muitas vezes, conectandose com demais termos para construir os relatos. Entre esses termos, podemos destacar: "parto"; "dor"; "cesárea"; "normal"; bebê"; "médica"; "médico"; "hospital”; "cesárea"; "violência";

Ademais, a partir do grafo percebemos que os agrupamentos (clusters) possuem bastante conexões entre si. São quatro as principais narrativas relacionadas à violência: a experiência vivida; o sentimento dos relatos; a solidão do partejar e os relatos de episiotomia.

Imagem 2: Conexões entre os termos presentes na categoria Compartilhamento de Experiência

Dossiê Crise, Feminismo e Comunicação - https://revistaecopos.eco.ufrj.br/

ISSN 2175-8689 - v. 23, n. 3, 2020

DOI: 10.29146/eco-pos.v23i3.27616 


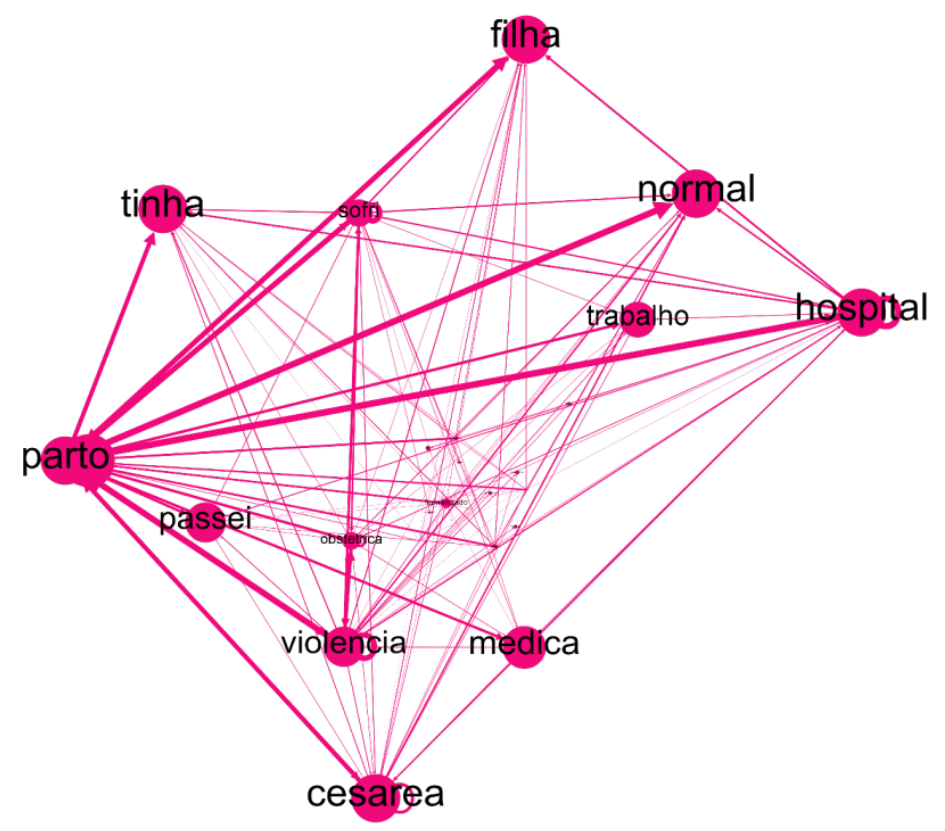

Fonte: - Grafo próprio criado a partir do Gephi

A conexão entre os termos representados pela cor rosa (Imagem 2) tem como principal discussão o "Compartilhamento das experiências", pontuando as narrativas dos procedimentos e violências pelas quais as mulheres passaram durante sua gestação, parturição e recuperação.

A conexão entre os termos "parto"; "normal"; "violência"; "hospital"; "sofri"; "obstétrica"; "barriga", revelam situações em que mulheres sofreram algum tipo de procedimento considerado como violência obstétrica, mas especificamente conectada à coesão de termos como "cesárea"; “ocitocina”; "episiotomia”. "fórceps"; "cesareana".

Vale ressaltar a presença dos agentes causadores dessas violências, pontuados pelo uso das palavras "médica"; "obstetra"; assim como as vítimas desses atos, identificados a partir de termos como "mulheres"; "mulher"; "mulheres"; "filha" e "feto".

Quadro 1: Comentários presentes na narrativa "Compartilhamento de Experiência”

Dossiê Crise, Feminismo e Comunicação - https://revistaecopos.eco.ufrj.br/

ISSN 2175-8689 - v. 23, n. 3, 2020

DOI: 10.29146/eco-pos.v23i3.27616 
Eu sofri violência obstétrica em hospital particular :C

Eu sofri violência no parto. Cesária forçada. 0 médico queria fazer meu parto na hora do almoço dele.

Meu primeiro PN, realizaram episiotomia sem consentimento. Quando me dei conta haviam me cortado e estavam dando os pontos, senti todos.

Fonte: - Dados presentes nas coletas das 98 páginas do Facebook

Imagem 3: Conexões entre os termos presentes na categoria Sofrimento da Violência

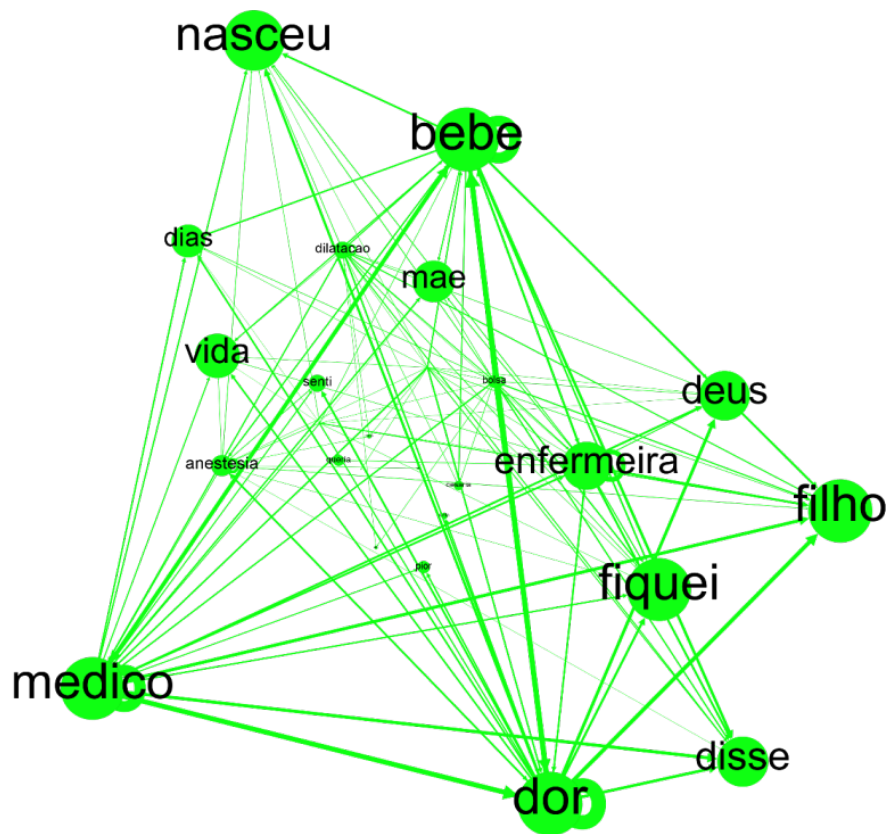

Fonte: - Grafo próprio criado a partir do Gephi

Já a partir agrupamento de cor verde (Imagem 3), além de também relacionarem os procedimentos considerados violentos, e pontuarem os agentes e vítimas desses atos, como os termos "médico"; "enfermeira"; "filho"; "mãe"; "bebê", destaca-se uma de suas particularidades: as narrativas de "Sofrimento da violência". 
Com termos tais quais: "dor"; "sofrimento"; "senti"; "pior"; "sinto"; "risco", pontuam suas experiências com a violência, não apenas narrando os procedimentos, mas sim, os adjetivando e relacionando-os com o que sentiram e os impactos deles em seu sofrimento. Sofrimento este que é narrado como efeito de uma relação médicopaciente abusiva.

Quadro 2: Comentários presentes na narrativa "Sofrimento da Violência"

Eu já estava nervosa e quando ela fez o exame de toque eu gemi de dor (acho que nada mais natural). Aí ela já começou a falar que mãe de primeira viagem é tudo manhosa.

Foi o momento mais terrível da minha vida, pedi pra morrer várias vezes, e sempre ouvindo a mesma palhaçada: primeiro filho tem que ser parto normal....

Verdade, fui mãe aos 16 anos e fui tratada pior que um cachorro, fui ignorada e depois de tudo ainda servi de cobaia para estagiários

Fonte: - Dados presentes nas coletas das 98 páginas do Facebook

Ainda vale destacar a recorrência do termo "Deus" entre estes comentários. Também atrelada a uma narrativa de sofrimento, usam esta palavra associada a termos como "graças" como forma de pontuar que apesar das violências sofridas, tudo finalizou de uma boa forma, mostrando um certo alívio de não haver impactos maiores na vida da mulher e de seu filho. Ademais, este termo também é usado em associação a palavras de alento como "conforte"; "abençoe"; "misericórdia"; "confortar", construindo comentários que, além de compartilharem suas experiências individuais, buscam apoiar outra mulher que sofreu com a violência obstétrica.

Quadro 3: Comentários presentes na narrativa "Sofrimento da Violência" com a presença da palavra Deus

Com dores...pedi cesária também no casa de saúde mas não quiseram... Mas graças a 
Deus, Deus me deu minha filha linda com vida e saúde.

Eu também passei por uma história similar da sua . Mas eu consegui salvar a minha filha. Que Deus abençoe vc e sua família!

Fonte: - Dados presentes nas coletas das 98 páginas do Facebook Imagem 4: Conexões entre os termos presentes na categoria Solidão da Violência

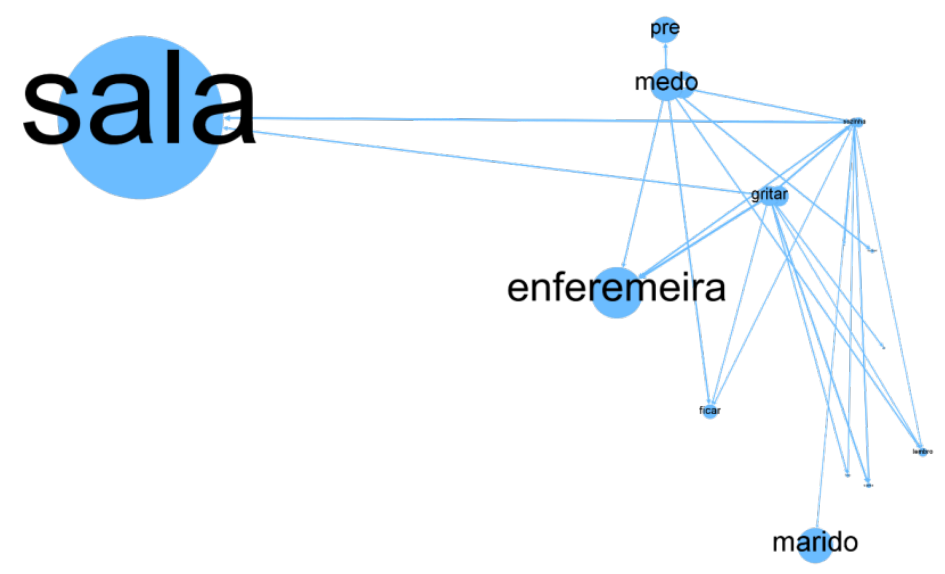

Fonte: - Grafo próprio criado a partir do Gephi

Por sua vez, os termos associados a cor azul (Imagem 4) demarcam a construção narrativa da "Solidão na violência". Palavras como "medo"; "sozinha" e "sala", mostram o relato das mulheres que se sentem abandonadas durante o trabalho de parto, sem, inclusive, a atenção dos profissionais que deveriam estar em contato com elas, como por exemplo, as enfermeiras.

Quadro 4: Comentários presentes na narrativa "Solidão na Violência"

Me deixaram 40 min na sala de parto em decúbito, amarrada, sozinha, esperando 


\section{dequitação.}

No parto da minha primeira filha eu fiquei super assustada com as dores as infermeiras mi largaram la sozinha ai teve uma hora que eu nao estava aguentando mais [...]

Fonte: - Dados presentes nas coletas das 98 páginas do Facebook

Entre os relatos de abandono, também podemos perceber a palavra "marido", que se relaciona ao impedimento dos companheiros em estarem presentes durante o trabalho de parto.

Quadro 5: Comentários presentes na narrativa "Solidão na Violência" com a presença da palavra marido

Nesse momento meu marido estava do lado de fora da enfermaria, o proprio medico fechou a porta, pois meu leito ficava bem na entrada proximo ao corredor.

No parto da minha bebê no hospital de Sobradinho a médica disse que meu marido não poderia acompanhar porque a sala de cirurgia obstetríca estava sendo lavada

Fonte: - Dados presentes nas coletas das 98 páginas do Facebook

Ademais, também retratam as "Ameaças de sofrimento" advindas de médicos e enfermeiros que exigem que as mulheres não façam barulho e "se comportem", caso contrários, serão deixadas sozinhas e com dor. Palavras como "gritar" e "gritei" demarcam essas ameaças.

Quadro 6: Comentários presentes na narrativa "Solidão na Violência" com a presença da palavra marido

Quando eu fui ganhar meu filho ouvi uma frase semelhante do médico que me atendeu, ele dizia: "se você não parar de gritar eu vou te deixar sofrendo aqui a noite toda" 
Quando o medico chegou na sala de parto ele falou "então é vc a escandalosa do hospital?, para de ser fresca que nem está doendo, se você não calar sua boca vc vai

$$
\text { parir sozinha ". }
$$

Fonte: - Dados presentes nas coletas das 98 páginas do Facebook

Imagem 5: Conexões entre os termos presentes na categoria Episiotomia como Relato

laceracao

\section{fizeram}

Fonte: - Grafo próprio criado a partir do Gephi

Por fim, a conexão entre os termos de cor amarela (Imagem 5) pontua acerca da "Episiotomia como relato". A partir de palavras como "laceração"; 'fizeram"; "corte"; "sutura"; "grau"; "incômodo", as mulheres relatam suas experiências a partir do procedimento de episiotomia por qual passaram. Além de narrarem o corte realizado pelos médicos, muitas vezes sem o consentimento da parturiente, as mulheres contam o procedimento do "ponto do marido", uma sutura realizada após o procedimento de episiotomia em que se aperta a entrada da vaginal.

Dossiê Crise, Feminismo e Comunicação - https://revistaecopos.eco.ufrj.br/

ISSN 2175-8689 - v. 23, n. 3, 2020

DOI: 10.29146/eco-pos.v23i3.27616 
Quadro 7: Comentários presentes na narrativa “Episiotomia como relato"

Eu cheguei na materno com $7 \mathrm{~cm}$ sem dor e ainda fui colocada no soro pra acelerar o parto e tiver corte sem necessidade tive 5 pontos

O médico dizer que "me deixou virgenzinha de novo" pro marido na consulta pós parto do primeiro. E ter cortado mesmo eu tendo dito antes pra não cortar e perguntado depois na sutura se queríamos "P, M ou G"

Fonte: - Dados presentes nas coletas das 98 páginas do Facebook

A partir de uma análise geral dos comentários, percebe-se a presença de um reforço da assimetria da relação médico-paciente. Assim, as mulheres reconstroem o discurso médico que ouviram e presenciaram que, além de se colocarem como os protagonistas da parturição, inferiorizam as mulheres. Essa inferiorização vai desde uma ideia de incapacidade feminina em partejar, passando pela ideia de que a função natural e por excelência do corpo feminino é a gestação e o parir, por isso, a elas não cabem escolhas e decisões. Enquanto aos médicos cabe o protagonismo do parto, às mulheres cabe a obediência e a aceitação das atitudes tomadas por eles.

Essa ideia de submissão da mulher em relação ao médico está também nos relatos de humilhação. Além de intervenções, por vezes desnecessárias e não consentidas, as mulheres são ofendidas, xingadas por alguns médicos que se colocam como seres superiores e detentores do saber e poder sobre o corpo da mulher.

Quadro 8: Comentários presentes na narrativa "Humilhação"

Eu fui obrigada a trocar lençol sujo de sangue da maca para um simples exame pra saber quanto de dilatação eu tinha é ouvir de uma médica que eu estava com frescura é não com contração 
então eu coloquei a mão pra ver se a bebê estava coroando foi no impulso só queria ver se ela ja estava vindo, ela me disse rindo com os alunos e a equipe, " Tire ja a mão dai pq se você toca em mim e eu chego em casa e meu marido sente o cheiro vai pensar oque de mim"..

Fonte: - Dados presentes nas coletas das 98 páginas do Facebook

Já em relação à visão da incapacidade da mulher em partejar, sendo necessária a presença de um profissional que conduza as intervenções, percebemos que toda ação referente ao ato de parir é uma decisão do médico, assumindo a centralidade do trabalho de parto, cabendo a ele, inclusive, a possibilidade de penalizar as mulheres que não aceitam as suas normativas. Como exemplo, pode-se observar os comentários abaixo:

Quadro 9: Comentários presentes na narrativa "Médico e a centralidade do trabalho de parto

não deixou meu marido entrar e também não me deixaram ver o neném quando tirou já foi levando ele sem motivo nenhum eu fiquei muito preocupada e comecei a chorar e ela com ignorância comigo dizendo "não sei pra quer chorar não tá sentindo dor! Vc tá é me atrapalhando."

"Quando eu falava que queria que ela entrasse ele dizia NÃO VOCÊ NÃO PARA DE GRITAR DE DOR,VOCÊ NÃO VAI VER A SUA MÃE”

"se você não parar de gritar eu vou te deixar sofrendo aqui a noite toda", e na hora das contrações quando ele vinha dar o "toque" ele falava com o semblante de deboche: "não está doendo nada"

Fonte: - Dados presentes nas coletas das 98 páginas do Facebook

A marca da negação no discurso médico também aparece como forma de intensificar a crítica em relação à sexualidade da mulher, a classificando como um 
ser em pecado por vivenciar a sua sexualidade, enquanto deveria exercer apenas para a sua função por excelência: a procriação.

Quadro 10: Comentários presentes na narrativa "Negação no discurso médico"

$$
\text { " vamos abre essa perna na hora de fazer não tava gostoso " }
$$

Como eu era muito nova senti que aquela equipe estava querendo me dar uma lição!

Não abriu a perna pra fazer, agora aguenta!

Elas gritavam: na hora dar vc num gostou? Já tá no sexto filho é pq gostou da dor parto!

Fonte: - Dados presentes nas coletas das 98 páginas do Facebook

Um dos maiores destaques que podemos perceber com relação às palavras presentes na categoria Relato de Violência seja a presença de verbos. 0 tempo verbal é destacado principalmente pelo uso do pretérito que, conforme Dias (2015, p. 188) demarca, "pertence ao mundo narrado, tempo esse ligado à situação comunicativa de relato".

Por se tratar de comentários que tem como objetivo contar a experiência de uma violência obstétrica sofrida, essas palavras se fazem importantes no contexto analisado. Assim, visualizamos verbos como: "levei"; "ficou"; "fizeram"; "incomodou"; senti"; "pegou"; "nasceu"; "disse"; "fiquei"; "tinha"; "teria"; "começou”. "feito"; "fiz"; "sofri"; "gritei”; “queria”.

Ainda na questão da presença de verbos, é interessante observar que existe uma divisão em relação a eles: a marcação da pessoa da ação. Desse modo, percebemos a presença da terceira pessoa, tanto no singular quanto no plural, que demarcam o agente da violência, sejam eles nomeados pelos termos "médica"; "médico"; "enfermeira" ou "obstetra"; assim como sujeitos que sofrem a violência, como: "marido"; "bebe"; "filha" e "filho". Além disso, ressalta-se a utilização de verbos na 
primeira pessoa do singular, que também caracterizam a pessoa que sofre a violência, e que no caso dos relatos de violência, personalizam a mulher parturiente.

Quadro 11: Comentários que mostram a marcação de verbos em seus relatos

Fiquei dois dias internada com contração, induziram meu parto e a dor era tão grande que me faltava ar e eu gritava pra poder respirar, a médica disse pra eu parar imediatamente pois ia assustar as outras mães, e me deixou lá por outras longas horas de tortura.

Quando tive minha primeira filha, levei tapas na cara de 2 enfermeiras, sem falar nas palavras humilhantes que ouvi durante as 18 horas de trabalho de parto.

Fonte: - Dados presentes nas coletas das 98 páginas do Facebook

\section{Considerações finais}

A violência obstétrica, ainda de conceituação recente, é um tema que tem se colocado em frequente debate, seja pelo ativismo que busca coibir sua prática, seja como assunto na mídia - matérias jornalísticas, casos específicos que ganham grande repercussão e produtos audiovisuais - ou como assunto controverso no âmbito político e institucional.

Com suporte da análise de conteúdo e a perspectiva de análise de narrativas em rede (MALINI, 2020), foi possível destacar acerca dos temas presentes entre os comentários de relatos de violência. Primeiramente, é preciso destacar que estes comentários (1.079) apresentam o segundo maior volume de dados quando comparado às outras categorias. Isso evidencia que os usuários agem em uma espécie de catarse, em uma necessidade de expor suas experiências, seja para validar a violência obstétrica - como o caso dos relatos que são associados às 
publicações que informam a violência ou a tipificam - ou seja como forma de criar uma relação de reconhecimento e pertencimento a um grupo - como os casos dos comentários que se relacionam às publicações de relatos de violência.

Já em relação às narrativas presentes entre os comentários, observamos que não há apenas o relato isolado da violência sofrida, e sim, pauta-se acerca do sofrimento que essas ações acarretam nas mulheres, assim como os sentimentos presentes em suas histórias, seja como forma de demonstrar a dor, solidão ou medo dos atos de violência e ameaças vindas dos médicos. Isso também é observado a partir do destaque dos termos utilizados. Apesar da presença de palavras que ressaltam alguns dos tipos de violência - como cesárea, ocitocina, fórceps e episiotomia (inclusive com uma narrativa bem presente) -, a construção dos relatos vai muito mais para o campo do sentimento, para a narrativa do sofrimento por qual as mulheres passaram do que demarcar quais os atos violentos que incidiram sobre seus corpos. A violência é destacada mais como uma imposição do poder médico acerca de seu corpo, fazendo destaque para o não consentimento das ações, humilhações proferidas e abandono do que uma tipificação ou nomeação do ato violento.

A luta pelo fim da violência obstétrica, inserida em um contexto de Quarta Onda do movimento feminista, se utiliza do compartilhar individual para se pontuar sobre questões comuns, uma espécie de performance de si para destacar problemas na sociedade. Destarte, compartilhar uma experiência individual acaba por criar uma experiência coletiva, em que demais usuárias se reconhecem no relato de outras, estabelecendo um vínculo de apoio mútuo. Uma rede de suporte em que os personagens ali envolvidos passam a se sentir pertencentes a um grupo.

Aqui vale um adendo sobre a potencialidade da manifestação em rede para as denúncias e para as repercussões na sociedade. Assim como o caso da campanha \#MeuAmigoSecreto, ocorrida em 2015 - um dos marcos da configuração dessa nova onda feminista - em que se questionou sobre os abusos sofridos pelas 
mulheres, a violência obstétrica também teve seus marcos na rede. 0 filme o Renascimento do Parto é um dos emblemas dessa mobilização e da forma como impulsionou as discussões para fora das redes, chegando aos meios de comunicação e ganhando espaços nos debates públicos. 0 marco mais recente é demarcado pela luta em considerar o termo Violência Obstétrica como legítimo, tornando-se oposição ao atual governo que tentou anular o seu uso. 0 papel do Ministério Público foi essencial para que o Ministério da Saúde voltasse atrás em posicionamento, contudo, não se pode esquecer da repercussão do tema nas redes e de como essa manifestação também fez com que a repercussão nos meios comunicacionais fosse ampliada. Ademais, é a partir das redes e do compartilhar de informações que muitas mulheres buscam apoio para além da questão psicológica, elas buscam conhecimento sobre como podem denunciar os casos de violência, bem como podem se prevenir da violência obstétrica a partir das informações ali compartilhadas.

Postas estas observações, compreendemos que as páginas do Facebook destinadas às discussões sobre violência obstétrica acabam por se tornar um território caracterizado como um suporte de pares, em que relatar uma própria experiência é uma forma de auxiliar o próximo ao mesmo tempo em que recebe apoio dos demais usuários. É naquele ambiente em que muitas mulheres se sentem confortáveis e seguras para contar suas histórias, pois sabem que ali serão compreendidas e reconhecidas como integrantes de um coletivo. São ambientes que servem para procurar informações outras - fora do contexto de grandes conglomerados comunicacionais - ou para se expor e buscar ajuda frente às violências sofridas.

\section{Referências bibliográficas}

AGUIAR, J.M. Violência institucional em maternidades públicas: hostilidade ao invés de acolhimento como uma questão de gênero. São Paulo, 2010

BANDEIRA, L. M. Violência de gênero: a construção de um campo teórico e de investigação.

Sociedade e Estado, 2014 
BOGADO, M. Rua. In: HOLLANDA, H. B. Explosão feminista: arte, cultura e universidade. [ebook]. São Paulo. Companhia das letras, 2018.

BUCHER, T. If... then: algorithmic Power and Politics. New York: Oxford University Preess, 2018

CONVENÇÃO DE BELÉM DO PARÁ. Organização dos Estados Americanos. Convenção Interamericana para Prevenir, Punir e Erradicar a Violência Contra a Mulher. Belém/PA (Brasil): Comissão Interamericana de Direitos Humanos, 1994.

COSTA, C. Rede. In: HOLLANDA, H. B. Explosão feminista: arte, cultura e universidade. [ebook]. São Paulo. Companhia das letras, 2018.

DIAS, M.M. Parâmetros na escolha de técnicas e ferramentas de mineração de dados. Acta Scintiarum. Maringá, v.24, n. 6. 2002

FREITAS, W. Plano de parto previne violência obstétrica. 2019. Disponível em: <https://www.ufpb.br/ufpb/contents/noticias/201cplano-de-parto-previne-violenciaobstetrica201d-alerta-pesquisadora-da-ufpb> Acesso em: 10 jan. 2020

LUZ, L.; GICO, V. As redes sociais digitais e a humanização do parto no contexto das Epistemologias do Sul. Revista Famecos, Porto Alegre, n.1, v.24. 2017

MALINI, Fabio. Quando tudo parecia ser tão distante daqui: a eclosão das narrativas sobre covid-19. 2020. Disponível em: <https://medium.com/@fabiomalini/quando-tudoparecia-ser-t\%C3\%A3o-distante-daqui-a-eclos\%C3\%A3o-das-narrativas-sobre-covid-1923ef531b1be1>

MINAYO, M.CS. O desafio do conhecimento: pesquisa qualitativa em saúde. São Paulo: Hucitec, 2007

MINISTÉRIO DA SAÚDE. Ofício no 017/2019. 2019. Disponível em: <encurtador.com.br/muNS2> Acesso em: 15 ago. 2019.

PARTO DO PRINCÍPIO. BRASIL. Governo Federal. Parirás Com Dor. Brasil, 2012.

SOUZA, D.S.; OLIVEIRA, T.C.F. "Na hora de fazer não gritou": A violência obstétrica nas mulheres parturientes. Universidade Católica do Salvador. Anais da $22^{\circ}$ Semana da Mobilização Científica - SEMOC. 2019

SOUZA, V.L.P. "Violência de gênero/Intolerância". In. COLLING, A.M.; TEDESCHI, L. A. (organizadores) Dicionário Crítico de Gênero. Dourados, MS : Ed. UFGD, 2015.

TELES, M.A.A.; MELO, M. 0 que é violência contra a mulher. [ebook]. São Paulo: Editora Brasiliense, 2017

VANZ, A. A.P. A violência obstétrica em (re)vista: uma análise discursiva. 2017. 143f. Dissertação (Mestrado em Letras) - Programa de Pós-Graduação em Letras. Universidade Estadual do Centro-Oeste Unicentro, Guarapuava, 2017

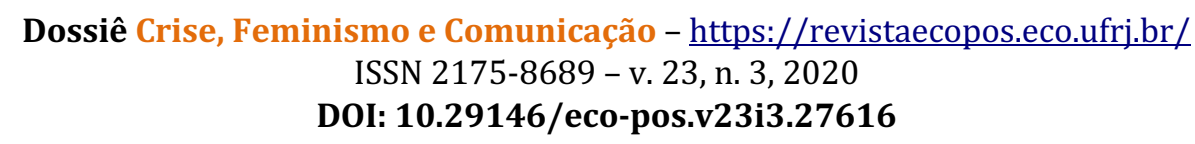


VARIKAS, E. Pensar o sexo e o gênero. Campinas: Unicamp, p. 17-53, 2016.

VAN DIJCK, J.; POELL, T.; DE WAAL, M. The platform society: public values in a connective world. New York: Oxford University Preess, 2018

VENEZUELA. Ley Orgánica sobre el Derecho de las mujeres a uma vida libre de violência, 2007 